PREPRINT

\title{
Temporal Variability and Context Specificity of Higher Education Teachers' Achievement Goals and Associations with Emotions and Satisfaction
}

\author{
Martin Daumiller \\ University of Augsburg \\ Julia Hein \\ University of Mannheim
}

\author{
Stefan Janke \\ University of Mannheim \\ Oliver Dickhäuser \\ University of Mannheim
}

\author{
Raven Rinas \\ University of Augsburg \\ Markus Dresel \\ University of Augsburg
}

\begin{abstract}
Previous research has demonstrated that achievement goals for teaching matter for student learning and teacher experiences. While prior studies focused primarily on how goals differ between individuals, educational theorists and practitioners have proposed that investigating variation within individuals may be more suitable for explaining daily experiences. To investigate the magnitude of within-person variation in goals, we distinguished between temporal variability and context specificity and tested their relevance for differences in teachers' subjective well-being. One-hundred-and-eight higher education teachers participated with 213 courses and 949 consecutive sessions across an average of five weeks. Before each session, teachers reported their current achievement goals, and after the session, their experienced emotions and satisfaction with the session. We used multilevel analyses to investigate sources of variation in these constructs. Results indicated that half of the variability in goal pursuit could be attributed to a stable-general fraction (between-level: different teachers), but that goal pursuit also had substantial amounts of variable-general (different semester weeks of the teachers), stable-specific (different courses of the teachers), and variable-specific (remaining session variance) fractions. Emotions and satisfaction also contained these four fractions to a substantial extent, exhibited lower stablegeneral fractions than goals, and were systematically related to the achievement goals, with different effects being observable for the different levels. Taken together, the present findings contribute to better understanding of how to conceptualize and assess teachers' goals and how they are intertwined with well-being.
\end{abstract}

Keywords: achievement goals, temporal variability, domain specificity, university teaching, emotions, teaching satisfaction

Education Impact Statement: We examined to which extent different higher education teachers pursue different goals, and to which extent a given teacher pursues different goals over time and across different contexts. Based on 108 higher education teachers who assessed their goals at the start of 949 sessions of different courses that they taught, we found that there are large differences between different teachers in the goals that they pursue, but that goals also depend on the semester-week, the respective course that was taught, and specifics of the current session. Further, we found that these differences in goal pursuit are systematically associated with the teachers' emotions during teaching and their satisfaction with their teaching.

THIS PAPER IS UNDER REVIEW.

Please do not cite or distribute any portion without authors' permission.

Prior research has pointed to the relevance of teachers' achievement goals for their teaching experiences

Correspondence concerning this article should be addressed to Martin Daumiller, Department of Psychology, University of Augsburg, Universitätsstr. 10, 86159 Augsburg, Germany; Martin.Daumiller@phil.uni-augsburg.de. ORCID: 0000-00030261-6143

The research reported in this article was supported by German Research Foundation Grant DI 929/5-1 to Oliver Dickhäuser and Grant DR 454/8-1 to Markus Dresel. (e.g., Butler, 2007; Daumiller et al., 2019; Dresel et al., 2013; Retelsdorf \& Günther, 2011). In particular, research suggests that achievement goals are important for teachers in terms of maintaining positive perspectives of their work, as reflected by direct associations with cognitive and affective measures of subjective well-being (e.g., Janke et al., 2019; Rinas et al., 2020; Retelsdorf et al., 2010). Notably, most of the research on associations between teachers' achievement goals and their well-being has focused on differences be- 
tween individuals (e.g., whether individuals with different goals also experience different emotions). In contrast, relatively little is known about the stability and intraindividual variability of teachers' goals and their affective and cognitive assessments of teaching. This is noteworthy, as scholars of achievement goals and emotions have made the claim that both goals and emotions strongly vary within individuals and situations (see Goetz et al., 2016; Seo \& Patall, 2021). It is highly important to acknowledge and investigate this within-variation in educational research - not only for developing a better theoretical understanding of these constructs and the psychological processes underlying them, but also for their application in practice, as intraindividual variation may be more susceptible to change within practical interventions. Here, we propose and test a model that allows for a fine-grained differentiation of variation in goal pursuit between and within individuals. We posit that both temporal variability and context-specificity represent independent aspects of goal variability. Specifically, our model elucidates the extent to which achievement goals for teaching depend on stable-general characteristics (between-teacher differences), variable-general aspects (such as different semester weeks), stable-specific aspects (such as different courses), and variable-specific aspects (such as different sessions), and how variability in these different fractions of goal pursuit is related to affective and cognitive aspects of subjective well-being. We investigate this in the underexamined population of higher education teachers to expand our knowledge of their goals, emotions, and satisfaction.

\section{Achievement Goals for Teaching}

The achievement goal approach distinguishes different types of goals that individuals can pursue to different strengths in achievement contexts and that go along with different affective, cognitive, and behavioral consequences (Hulleman et al., 2010). Fundamentally distinguished are mastery aims (development of own competence and task mastery) and performance aims (demonstration of competence and performance relative to others) as well as a focus on approaching success or avoiding failure. This leads to four types of goals: mastery approach, mastery avoidance, performance approach, and performance avoidance (Elliot \& McGregor, 2001). Especially in the literature on teachers' achievement goals, two further types of goals are frequently considered given their relevance in the teaching and work context (Butler, 2012): work avoidance goals (striving to get through the day with little effort) and relational goals (striving to create close and caring relationships with students). Faculty members have been found to show (inter-)individual differences in the strength of pursuit of these goals, which in turn was found to be associated with teaching quality, attitudes, learning, and affect (e.g., Daumiller et al., 2016, 2019, 2020, 2021a; Hein et al., 2019, 2020; Rinas et al., 2020).

Researchers acknowledged that a finer differentiation and disentanglement based on the content of mastery- and performance-based goals is necessary, as conflating different goal facets can lead to distorted findings on the assciations of achievement goals (Elliot \& Hulleman, 2017; Grant \& Dweck, 2003; Hulleman et al., 2010). Therefore, performance goals have been distinguished (see Elliot \& Hulleman, 2017; Hulleman et al., 2010; Lee \& Bong, 2016; Senko \& Dawson, 2017) based on an appearance component (wanting to be perceived as competent or not wanting to be perceived as incompetent, irrespective of personal performance) and a normative component (wanting to be more competent than others or not worse than others concerning actual performance). Mastery goals have been distinguished (e.g., Elliot, et al., 2011) according to whether the standard for evaluating one's own competence lies in the task ("task goals") or in one's intrapersonal development ("learning goals"). As these two mastery-based components (task, learning) and two performancebased components (appearance, normative) demonstrate differential associations with potential outcomes (Daumiller et al., 2019), we use the same goal distinction in order to contribute to a clear and detailed understanding of these goals. Given that several studies on higher education teachers in particular have found little predictive power of task and learning avoidance goals (e.g., Daumiller et al., 2019; Rinas et al., 2020), we do not investigate them here (see also Murayama et al., 2011). To parallel this and for increased clarity, we also focus performance goals solely on the appearance component, as we expect this aspect to be primarily tied to emotional experiences (see Daumiller et al., 2019; Rinas et al., 2020). ${ }^{1}$

\section{Temporal Variability and Context Specificity of Achievement Goals for Teaching}

Preferences for achievement goals contain fractions that are rather stable or variable over time (Bürger \& Schmitt, 2017; Fryer \& Elliot, 2007; Muis \& Edwards, 2009; Jagacinski et al., 2010; Praetorius et al., 2014). Moreover, they are considered partly general and partly context-specific (e.g., Bong, 2001, 2004; Sparfeldt et al., 2015). In a first attempt to further differentiate different parts of variation, Praetorius et al. (2014) proposed a model on the temporal stability of goal pursuit 


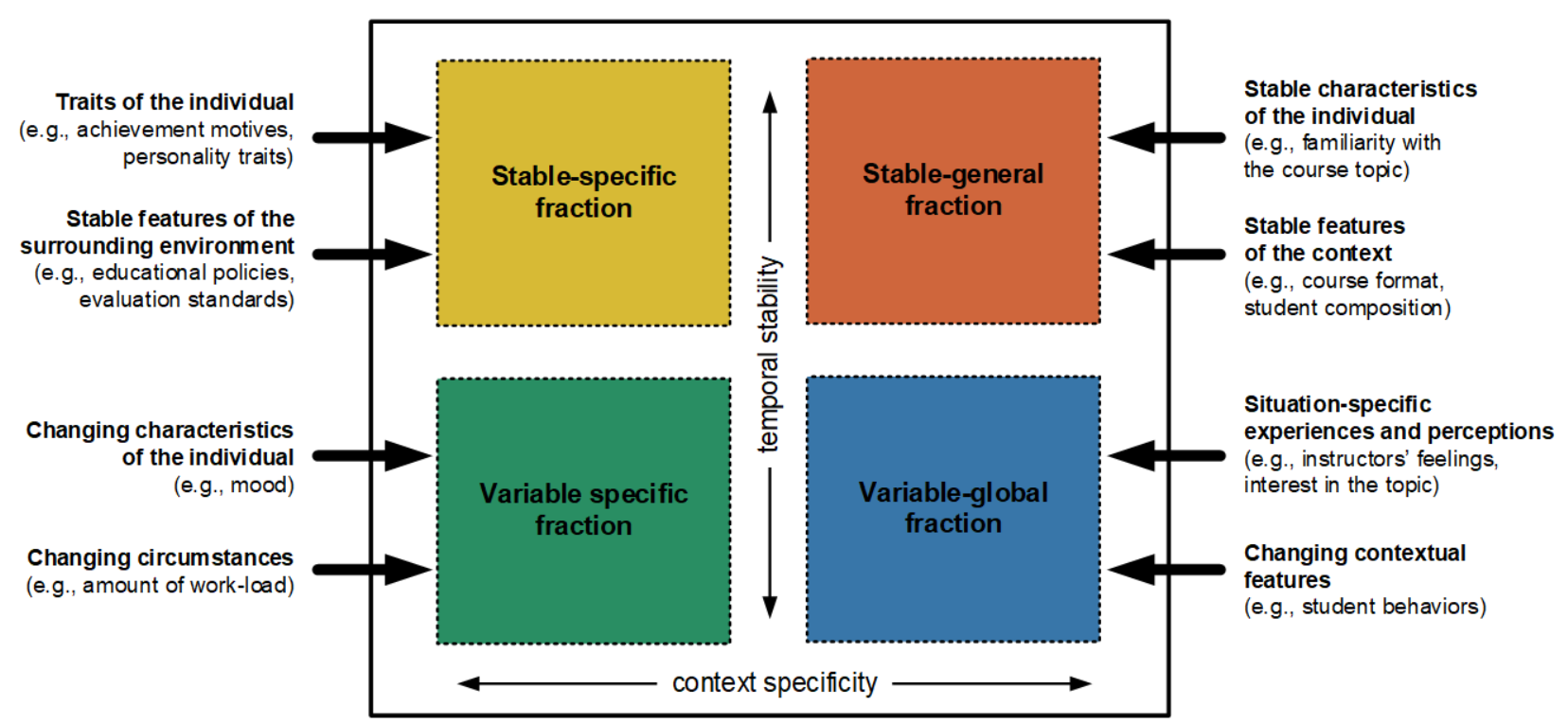

Figure 1. Conceptual framework for the temporal variability and context specificity (based on Praetorius et al., 2014)

in teachers. This model however only considered temporally stable and temporally variable aspects, but did not further differentiate as to whether variation was bound to the respective specific situation or not. We thereby amended the model to additionally incorporate this important source of variation (depicted in Figure 1).

The most investigated source of variation is stable variation between individuals (stable-general fraction). This between-person variation is bound to general traits of the individual, such as achievement motives or personality traits, and stable features of the overall surrounding institution, such as educational policies and evaluation standards. Within-person variation, in turn, can be based on changing characteristics of the individual that are not situation-specific, such as one's current mood, and changing general circumstances, such as work-load (variable-general fraction). Further, within-person variation can also be attributed to context-specific factors (such as the different courses taught by a teacher): Specifically, variation can depend on stable characteristics of the different courses, such as an individual's familiarity with the topic of the course or the teaching format of the course (stable-specific fraction). Finally, currently pursued teaching goals may also depend on situation-specific experiences and perceptions, such as teachers' feelings and their interest in the current topic, as well as changing contextual features, such as students' behaviors in a given session (variable-specific fraction).

Empirical investigations exploring the temporal variability of achievement goals are mainly based on samples of students (for an overview see Scherrer et al.,
2019) and athletes (see Daumiller et al., 2021b, for an overview). The stability of goals (retest correlations) ranged between $r=.40$ and $r=.70$ (Senko et al., 2011). Regarding achievement goals for teaching, the few existing studies show that goals contain about half stable and half variable fractions over time, with mastery goals often being more variable than the other goals (Praetorius et al., 2014; see also Muis \& Edwards, 2009). For faculty members, first investigations indicate similar stability coefficients regarding context-unspecific achievement goals of academic staff members on a day-to-day basis (Janke \& Dickhäuser, 2018) as well as achievement goals in the research domain across half a year (Daumiller \& Dresel, 2020a). Based on these rather similar findings across different populations, domains, and time intervals, it can be expected that also across multiple weeks, achievement goals for teaching should contain both a substantial part of temporally stable as well as a substantial part of temporally variable fractions. At the same time, these findings also highlight that there is more to variation in goals than inter-individual differences.

Concerning the specificity across different domains or contexts, the few studies that exist have solely focused on the student level (e.g., Bong, 2004; Sparfeldt et al., 2015). Here, findings point to correlations across different subjects around $r_{\text {mean }}=.41-.79$ (Sparfeldt et al., 2015), with mastery goals being more prone to situational variation than performance goals. To the best of our knowledge, context specificity has never been investigated for achievement goals for teaching. Analogous to subjects for students, the most natural contexts here, are different courses. Based on the argument that 
achievement goals change when environments change (e.g., Fryer \& Elliot., 2007), it can be expected that teachers pursue different goals within different courses. An important premise to this end is that achievement goals have been found to be invariant for the two superordinate work domains of faculty members, teaching and research, with teaching and research goals sharing around half of their variability (Daumiller \& Dresel, 2020a). Being invariant across the two superordinate work domains and sharing variability between them, achievement goals should also be invariant across different courses that teachers are teaching and contain a substantial part of general context-specific variable fractions.

In order to more thoroughly understand the variability of achievement goals, it is necessary to simultaneously consider temporal variability and context specificity (which are often confounded when only examining one aspect) by investigating sessions in different courses of different teachers over time. Considering current achievement goals regarding sessions of different courses taught by different teachers over multiple weeks allows us to investigate the magnitude of stablegeneral, stable-specific, and variable-general fractions, and see how much variance remains on the variablespecific level. Knowledge regarding the magnitude of these fractions is highly relevant for conducting research on these constructs (study design; measurement design; formulation of appropriate research questions regarding the operationalization of the constructs), as well as their application in practice (correct interpretation of results and deriving appropriate implications; see Praetorius et al., 2014; Murphy \& Alexander 2000; Pintrich, 2000). Further, these findings will facilitate a better understanding of the respective constructs from a theoretical perspective. For example, researchers have inquired about the stability of mastery goals that have been found to be less stable/general than other types of achievement goals (Praetorius et al., 2014; see also Muis \& Edwards, 2009). To better understand this, it is helpful to find out whether this is because these types of goals are less stable due to temporal changes (e.g., different priorities or resources available) or due to different contexts (which may offer different task and learning affordances). Disentangling the different fractions of goal variability also sets the stage for elucidating their interplay with teachers' emotions and satisfaction, which are central to teachers' subjective wellbeing.

\section{Teaching Emotions and Satisfaction and their Rela- tionship with Achievement Goals}

Teachers' subjective well-being plays a key role in educational contexts, particularly regarding teacher retention and student experiences and learning (e.g., Frenzel et al., 2016; Stunpisky et al., 2016). Teachingrelated emotions and satisfaction form central aspects of teachers' subjective well-being (Authors, anonymized; Diener et al., 2009). To this end, emotions can be understood in terms of a two-dimensional taxonomy including valence and activation components (Pekrun et al., 2011). While the valence component differentiates emotions as being positive or negative, the activation component focuses on whether emotions are activating or deactivating. Based on this distinction, we focus on teachers' enjoyment and pride, anxiety, shame, and boredom while teaching. Enjoyment and pride encompass positive/activating emotions, while anxiety and shame are negative/activating emotions, and boredom constitutes a negative/deactivating emotion. These emotions in particular have been found to be frequently experienced within school and higher education teaching contexts and seem to be highly relevant therein for teaching-related processes (see e.g., Frenzel et al., 2016; Stunpisky et al., 2016, 2019; Thies \& KordtsFreudinger, 2019). Besides emotions, satisfaction refers to a cognitive evaluation of how content a teacher is with their teaching, which has been linked with their occupational health (Parker et al., 2012; Skaalvik \& Skaalvik, 2011). Investigating both emotions and satisfaction, as we do in the present study, can thereby be considered a relevant combination for understanding how teachers are faring within their teaching. Similar to achievement goals, emotions have between- and within-person variation, which likely also holds true for teaching satisfaction as well (see Nett et al., 2017, for an overview). In particular, the same fractions of temporal variability and context specificity can also be expected for these constructs, but have not yet been jointly examined. For example, emotional experiences have been found to be about half temporally stable and half variable (e.g., Nett et al., 2017; Respondek et al., 2019; Yasuda et al., 2016), and can vary considerably depending on the subject and group of students being taught (Frenzel et al., 2015).

Achievement goals are posited to guide one's attentional focus and appraisals, and in turn, are linked with different emotions and levels of satisfaction (Authors, anonymized; Pekrun et al., 2006, 2009). Following this logic, empirical studies have established a close link between these constructs in students (Huang, 2011; Senko et al., 2011). However, for teachers, aside from 
a handful of studies which we draw on to guide the present research, such associations are rarely investigated. Specifically, mastery goals are thought to entail a focus on mastery of an activity, controllability, as well as on the positive value of the activity, resulting in increased positive activity emotions (e.g., enjoyment) and satisfaction, and decreased negative activity emotions (e.g., boredom). Performance approach goals are centered around perceived controllability and the positive value of outcomes, thereby facilitating increased positive outcome emotions such as pride and satisfaction. Lastly, performance avoidance goals are proposed to be focused on perceived uncontrollability and negative value of negative outcomes, evoking negative outcome emotions (e.g., anxiety, shame) and decreased satisfaction. Theoretical linkages with emotions and satisfaction can also be presumed for relational and work avoidance goals. Relational goals, given their emphasis on developing personal and caring interrelations with students, may foster positive emotions as well as satisfaction in teachers. This may especially be the case as the quality of student-teacher interactions can be considered an important social factor contributing to teachers' well-being (Kiltz et al., 2020; Wang et al., 2016). In contrast, work avoidance goals are typically characterized as being harmful and are paired with demotivation as well as risk for suboptimal performance (see King \& McInerney, 2014). Based on this maladaptive nature and lack of effort, such goals can be expected to be tied to negative emotions and reduced satisfaction.

These theoretical expectations are largely reflected in empirical studies. For example, in their study on school teachers, Wang et al. (2016) found mastery and relational goals to be associated with more enjoyment, and work avoidance goals to be associated with less enjoyment and more anxiety and anger. Similarly, Janke et al. (2019) documented that school teachers' mastery goals were positively linked with enjoyment, while their performance approach goals were negatively related to anxiety, and their performance and work avoidance goals were positively related to anxiety and negatively related to enjoyment. In terms of higher education teachers, Rinas et al. (2020) found learning approach goals to be positively related to enjoyment and negatively related to anger and boredom, while appearance approach goals were positively related to pride and appearance avoidance goals were positively related to anxiety and shame. Relational goals were also positively related to shame and boredom, while work avoidance goals were negatively related to enjoyment and positively related to shame and boredom. Studies have also found similar results regarding teachers' satisfaction. For example, Papaioannou and Christodoulidis (2007) found that school teachers' mastery goals were positively, and performance avoidance goals were negatively associated with their job satisfaction. Moreover, Retelsdorf et al. (2010) noted that teachers' mastery goals were linked with lower burnout, while their performance and work avoidance goals were linked with higher burnout. Based on these initial studies, it is clear that achievement goals are intricately intertwined with teachers' emotions and satisfaction.

These relationships may differ on an inter- and an intra-individual level, which are typically statistically independent from one another and can produce opposite relationships (Murayama et al., 2017). Most of the empirical research on achievement goals (and also emotions; see Becker et al., 2015; Frenzel et al., 2015 regarding teachers) has relied on between-person analyses while within-person analyses are lacking (Murayama et al., 2017; cf. Goetz et al., 2016; Seo \& Patall, 2020). The existing research did not indicate variation in relationships depending on the level of investigation (Goetz et al., 2016). However, it is still unclear whether this finding holds when considering finer conceptualizations of between- and within-person variation (see Figure 1 for an overview) outside of student populations.

Regarding differential associations, it might be the case that certain linkages between achievement goals and emotions only enfold with regard to their stable/general fractions: Stable-general tendencies orienting an individual towards mastery when teaching may go along with better preparation of one's teaching and better interpretations of challenges therein, resulting in more positive and less negative emotions. In turn, having stronger mastery goal strivings in one particular course compared to other courses may not necessarily go along with more adaptive emotional experiences when teaching this course, but could rather be a function of how familiar one is with this course: Teaching a course for the first time could be tied to stronger mastery goal strivings that do not evoke joy or satisfaction with teaching, as one's focus when teaching in this context may lie in developing new teaching materials, which can be demanding and straining. Furthermore, teachers may experience setbacks and failures in the process, which could cause immediate frustration and anger. Performance avoidance goals, in turn, might primarily matter with regard to temporally variable and context-specific fractions: Pursuing stronger performance avoidance goals in a particular session than usual should go along with increased worries to avoid 
making a bad impression, which in turn should be linked to less positive and more negative emotions. On the stable-global level, pursuing such goals might instead go along with increased time for and more thorough preparation of one's classes, which counteract the detrimental effects that such goals may hold for affective experiences (see Daumiller et al., 2021a, for a similar argument). Finding such differences can therefore be deemed as very helpful for better understanding and deriving implications surrounding the processes linking achievement goals with emotional experiences and satisfaction (see Voelkle et al., 2014).

\section{Research Questions}

The main aim of the present work was to investigate the variability of higher education teachers' achievement goals for teaching and their associations with affective and cognitive assessments of teaching. Specifically, we wanted to elucidate the magnitude of temporal variability and context specificity in higher education teachers' achievement goals. In line with previous research, we hypothesized that a significant portion of variance can be attributed to stable-general fractions and that a substantial portion of variance can also be attributed to temporally variable as well as to context-specific fractions. For emotions and teaching satisfaction, we had the same expectations.

Adding to this, we also aimed to investigate the interrelations between achievement goals and discrete emotions as well as teaching satisfaction. Based on the aforementioned points, we assumed positive linkages with enjoyment, pride, and satisfaction and negative linkages with boredom and shame for mastery-based goals, performance approach, and relational goals. Further, we assumed negative linkages with enjoyment, pride, and satisfaction and positive linkages with boredom and shame for performance avoidance and work avoidance goals. We tested these associations by investigating whether variability in goal pursuit regarding the different fractions outlined above also went along with variability in emotions and satisfaction regarding these fractions. We had no specific expectations concerning differences in associations based on these fractions and investigated this on an explorative level.

\section{Method}

To answer our research questions, we conducted a micro-longitudinal study in which higher education teachers filled out questionnaires about their current goals for teaching their sessions. The participating teachers completed surveys over multiple courses for multiple weeks and regarding specific sessions. They answered questions about their achievement goals immediately before the sessions started and reported their experienced emotions and satisfaction after the end of the session. In each course, we examined the first five sessions of the term.

\section{Sample}

Altogether 108 teachers $\left(58 \%\right.$ with $\mathrm{PhD}^{2}$, thereof $21 \%$ full professors; $49 \%$ female; mean age: 40.7 years, $S D=10.6)$ from two German universities participated with 213 courses (two courses on average per teacher) and a total of 949 sessions.

\section{Measurements}

To enable high participation and acceptance by the participants, a concise assessment within the sessions was required. Therefore, we used established single item and short measures. The reliability and validity of such an approach has been supported for measuring motivations and experiences. In particular, studies on this topic (see e.g., Goetz et al., 2007; Gogol et al., 2014; Wright \& Zimmermann, 2019) document that single-items work especially well and adequately in the case of constructs such as goals and emotions. In our case, we used easily answerable measures that had been already validated as single items in past research (Daumiller et al., 2021b; Goetz et al., 2016).

\section{Achievement goals}

Achievement goals were assessed using single items from the higher education teaching achievement goal inventory by Daumiller et al. (2019). Following the item stem ("In today's session of this course, it is my goal to ..."), the participants made assessments regarding their task approach ("... conduct my teaching tasks as well as possible"), learning approach ("... further develop my own competences as much as possible"), appearance approach ("... that other people notice how good my teaching is"), appearance avoidance (“... that others don't think my teaching is bad"), relational ("... achieve a personal connection with students"), and work avoidance goals ("... have the least amount of work as possible"). Convergent validity with the full scale and reliability of these single items has been confirmed in prior research (Daumiller et al., 2021b). Each item was to be answered on Likert type scales ranging from 1 (do not agree at all) to 8 (agree completely).

\section{Discrete emotions}

We assessed teachers' emotions using single item measures by Goetz et al. (2016). Following the item stem "In today's session, I experienced...", participants rated the extent to which they experienced anxiety ("... anxiety"), enjoyment (“... enjoyment"), boredom (“... boredom"), shame ("... shame"), and pride ("... pride"). At the end of the session, participants re- 
Table 1

Descriptive Results and Decomposition of Variance for Session, Course, Week, and Teacher

\begin{tabular}{|c|c|c|c|c|c|c|c|c|}
\hline & \multicolumn{4}{|c|}{ Descriptive statistics } & \multicolumn{4}{|c|}{$\begin{array}{c}\text { Variance fractions (ICCs) } \\
\text { with } 95 \% \text {-confidence intervals }\end{array}$} \\
\hline & $M$ & $S D$ & Range & Skew & $\begin{array}{l}\text { Session } \\
\text { (variable- } \\
\text { specific) }\end{array}$ & $\begin{array}{c}\text { Course } \\
\text { (stable- } \\
\text { specific) }\end{array}$ & $\begin{array}{c}\text { Week } \\
\text { (variable- } \\
\text { general) }\end{array}$ & $\begin{array}{l}\text { Teacher } \\
\text { (stable- } \\
\text { general) }\end{array}$ \\
\hline \multicolumn{9}{|l|}{ Achievement goals } \\
\hline Task approach & 7.17 & 1.18 & $1-8$ & -1.99 & $.33[.27 ; .41]$ & $.06[.02 ; .11]$ & $.20[.14 ; .27]$ & $.40[.30 ; .49]$ \\
\hline Learning approach & 5.11 & 2.00 & $1-8$ & -0.40 & $.14[.11 ; .17]$ & $.03[.01 ; .05]$ & $.19[.14 ; .26]$ & $.64[.56 ; .71]$ \\
\hline Performance (appearance) approach & 4.51 & 2.06 & $1-8$ & -0.23 & $.11[.09 ; .14]$ & $.04[.02 ; .06]$ & $.20[.15 ; .26]$ & $.65[.57 ; .72]$ \\
\hline Performance (appearance) avoidance & 4.81 & 2.34 & $1-8$ & -0.24 & $.14[.11 ; .18]$ & $.02[.01 ; .04]$ & $.14[.10 ; .19]$ & $.70[.62 ; .76]$ \\
\hline Relational & 5.23 & 1.84 & $1-8$ & -0.47 & $.12[.10 ; .16]$ & $.08[.05 ; .12]$ & $.12[.09 ; .17]$ & $.67[.59 ; .74]$ \\
\hline Work avoidance & 3.02 & 1.98 & $1-8$ & 0.76 & $.16[.13 ; .20]$ & $.03[.01 ; .05]$ & $.19[.14 ; .25]$ & $.62[.55 ; .69]$ \\
\hline \multicolumn{9}{|l|}{ Emotions } \\
\hline Enjoyment & 6.52 & 1.31 & $1-8$ & -1.01 & $.33[.28 ; .41]$ & $.13[.07 ; .20]$ & $.20[.14 ; .27]$ & $.34[.23 ; .43]$ \\
\hline Pride & 3.91 & 2.09 & $1-8$ & 0.02 & $.24[.19 ; .30]$ & $.03[.00 ; .05]$ & $.17[.12 ; .23]$ & $.57[.48 ; .65]$ \\
\hline Anxiety & 1.50 & 1.05 & $1-8$ & 2.86 & $.42[.35 ; .50]$ & $.07[.02 ; .13]$ & $.13[.07 ; .19]$ & $.38[.28 ; .47]$ \\
\hline Shame & 1.38 & 0.88 & $1-7$ & 3.00 & $.30[.25 ; .36]$ & $.14[.08 ; .21]$ & $.26[.19 ; .33]$ & $.31[.20 ; .41]$ \\
\hline Boredom & 2.06 & 1.53 & $1-8$ & 1.67 & $.48[.40 ; .56]$ & $.10[.04 ; .16]$ & $.15[.08 ; .22]$ & $.28[.18 ; .37]$ \\
\hline Satisfaction & 6.69 & 1.25 & $1-8$ & -1.62 & $.40[.33 ; .48]$ & $.07[.02 ; .12]$ & $.20[.13 ; .27]$ & $.34[.24 ; .43]$ \\
\hline
\end{tabular}

Note. $N=949$ session-specific assessments that are clustered within 213 courses and 108 teachers, and within 5 measurement points corresponding to the first five weeks of the term. The theoretical range of all variables is $1-8$. For a visualization of the ICC values, see Figure 3.

sponded to their emotions experienced during the session using a five-point Likert-type scale from 1 (not at all) to 5 (very strongly).

\section{Satisfaction}

We measured participants' satisfaction with the respective session using two self-constructed items ("Overall, I am satisfied with today's session" / "Considering what I intended for today's session, I am satisfied"; $r=.92$ ) that were to be answered on Likert type scales ranging from 1 (do not agree at all) to 8 (agree completely).

\section{Analyses}

To investigate the temporal variability and context specificity of goals, we estimated variance fractions for variable-specific fractions (sessions), stable-specific fractions (courses), variable-general fractions (assessments of a teacher in a given week of the semester), and stable-general fractions (teachers). Here, sessions are nested within courses and assessments for each semester week, which both in turn are nested within teachers (Figure 2). To yield the corresponding intra-class-correlations (ICCs), we estimated cross-classified random intercept multilevel models with the lme4-package in $\mathrm{R}$ and used the included parametric bootstrap bootMerfunction to calculate $95 \%$-confidence intervals for the
ICCs (based on 1000 iterations that used different values of the random effects that were drawn from a Normal distribution using the parameters derived from the mixed model). We employed the analogous procedure to investigate these different fractions in discrete emotions and teaching satisfaction.

To analyze the effects of goals on emotions and satisfaction, we considered those fractions of temporal stability and context specificity that were found to contain substantial variance on average for both goals and emotions/satisfaction. Regarding these, we estimated multi-level analyses for each dependent variable (emotions, satisfaction) which were regressed on all achievement goals. Additionally, we modelled correlations between the goals. We tested for potential multicollinearity issues in all models by comparing the parameter estimates with the bivariate correlations and systematically excluding predictors. We used Mplus (Muthén \& Muthén, 2017) and conducted Bayesian analyses that considered the categorical scale format of the emotions. There were only few missing values $(<2.4 \%$ per item $)$ that were dealt with model-based, using the FIML method (Peugh \& Enders, 2004). 


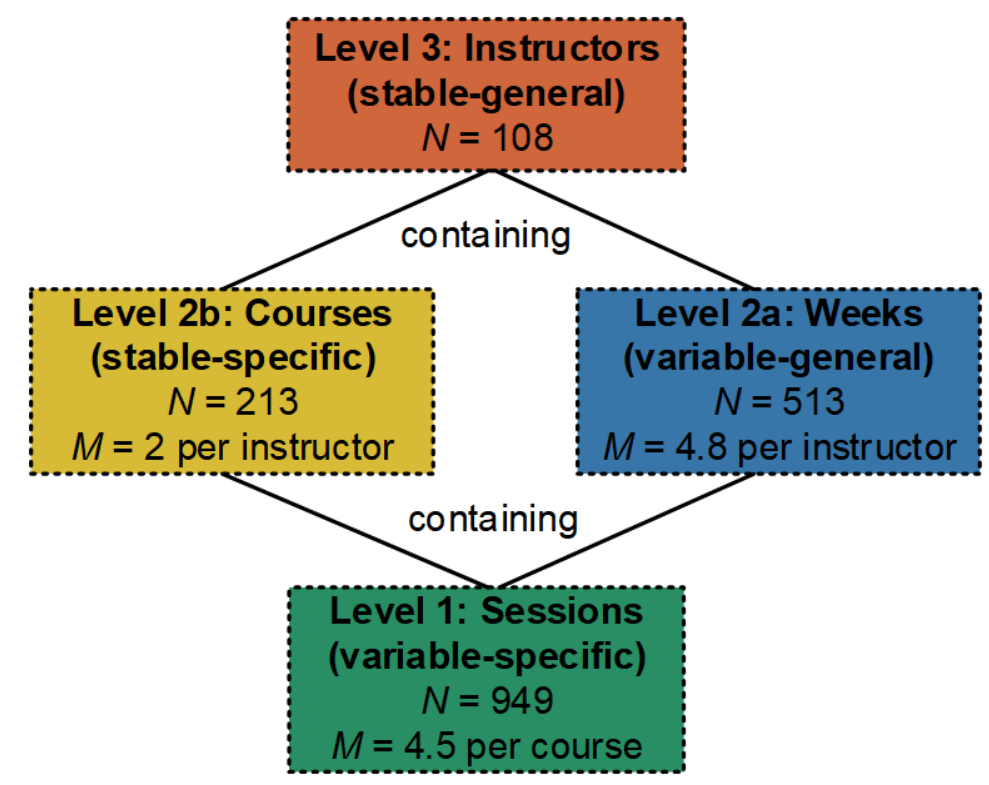

Figure 2. Overview of the different levels that were used for the estimation of variance fractions in the analyses of temporal variability and context specificity.

\section{Results}

Descriptive results pointed to similar mean levels and variances of achievement goals and emotions as observed in prior research (strong mastery goals, relatively few negative emotions; e.g., Daumiller et al., 2019; Rinas et al., 2020). At the same time, there was a rather large magnitude of variance in the session-specific assessments of the achievement goals and emotions (Table 1), which we used in the subsequent multilevel models to determine how strongly this variability could be attributed to the different courses (stablespecific fraction), week (variable-general fraction), and teachers (stable-general fraction), and how much variability remained on the session-level (variable-specific fraction).

Temporal Variability and Context Specificity of Goals, Emotions, and Satisfaction

The decomposition of the variance fractions (see Table 1) indicated that a large amount of the variance in the pursued achievement goals could be attributed to stable differences between different teachers (ICC teacher $=.40-.70$ ). The remaining variance could be attributed to substantial extent to both temporally variable (ICC session and week $=.24-.54$ ) as well as context specific fractions (ICC session and course $=.15-.39$ ). Among them, the course-specific variability (i.e., variable-specific fraction) was quite small, albeit still substantial and different from nil, especially for task approach and relational goals. With the exception of task goals, which had less stable-general fraction and higher variability remaining on the session level, the stablegeneral fractions were larger than the other fractions (non-overlapping confidence intervals). This means that a little more than half of the variability in goal pursuit could be attributed to different teachers, with the remaining variability being attributable to both temporally variable as well as context-specific aspects.

For affective and cognitive assessments of teaching, we also found that all four fractions exhibited substantial amounts of variability (with the exception of pride, which was not systematically related to different courses). Compared to the goals, the stable-global fraction was descriptively smaller, while the specific fractions were larger. Given that the variability on the course level was not substantial for all variables and descriptively rather small, we did not consider this level further for investigating the associations between goals and emotions/satisfaction experienced. Instead, we only considered their relations on the remaining three levels, rendering a hierarchical three-level design (multiple sessions nested within different teaching weeks of different teachers). ${ }^{3}$

\section{Associations with Discrete Emotions and Satisfac- tion}

Regarding these three levels, the correlations between all variables (Table 2), pointed to systematic associations between goals and emotions that were well 
in line with the results of the subsequently reported regression analyses. Investigation of these correlations Table 2 goals in a specific session was tied to experiencing less joy in the very session.

Three-Level Correlations of Achievement Goals, Emotions, and Satisfaction

\begin{tabular}{|c|c|c|c|c|c|c|c|c|c|c|c|}
\hline & 1 & 2 & 3 & 4 & 5 & 6 & 7 & 8 & 9 & 10 & 11 \\
\hline \multicolumn{12}{|l|}{ Achievement goals } \\
\hline \multicolumn{12}{|l|}{ [1] Task approach } \\
\hline [2] Learning approach & $.16 / .46 / .46$ & & & & & & & & & & \\
\hline $\begin{array}{l}\text { [3] Performance } \\
\text { (appearance) approach }\end{array}$ & $. \mathbf{2 4} / . \mathbf{5 5} /-.02$ & $.17 / .43 / .13$ & & & & & & & & & \\
\hline $\begin{array}{l}\text { [4] Performance } \\
\text { (appearance) avoidance }\end{array}$ & $.12 / .27 / .13$ & $.21 / .11 / .15$ & $.20 / .48 / .76$ & & & & & & & & \\
\hline [5] Relational & $.18 /-.17 / .22$ & $.25 /-.25 / .29$ & $.15 /-.16 / .26$ & $.06 /-.01 / .28$ & & & & & & & \\
\hline [6] Work avoidance & $-.18 /-.09 /-.37$ & $7-.12 / .05 /-.17$ & $-.09 / .11 / .22$ & $-.12 / .15 / .22$ & $.03 /-.07 / .14$ & & & & & & \\
\hline \multicolumn{12}{|l|}{ Emotions } \\
\hline [7] Enjoyment & $.11 / .17 / .58$ & $.01 / .15 / .44$ & $.07 / .14 / .12$ & $-. \mathbf{1 6} / . \mathbf{3 8} / .09$ & $-.01 / .40 / .37$ & $.08 /-.01 /-.32$ & & & & & \\
\hline [8] Pride & $.15 / .17 / .09$ & $.02 / .20 / .21$ & $.00 / .16 / .57$ & $-.02 / .36 / .49$ & $-.02 / .33 / .36$ & $-.12 / .48 / .14$ & $.49 / .55 / .32$ & & & & \\
\hline [9] Anxiety & $.02 /-.25 /-.38$ & $.13 /-.22 / .07$ & $.10 / .11 / .18$ & $.02 /-.08 / .26$ & $.03 /-.15 / .18$ & $-.11 / .09 / .39$ & $-.14 /-.49 /-.10$ & $.01 /-.32 / .63$ & & & \\
\hline [10] Shame & $-.23 / .35 /-.43$ & $-.02 / .30 /-.07$ & $-.04 / .28 / .05$ & $.13 /-.02 / .20$ & $-.06 /-.37 / .15$ & $-.02 / .13 / .46$ & $-.39 /-.25 /-.19$ & $9-.30 /-.08 / .51$ & $.62 / .07 / .91$ & & \\
\hline [11] Boredom & $-.04 /-.23 /-.44$ & t.08/-.20/-.14 & $-.05 /-.12 / .23$ & $.09 / .12 / .18$ & $.08 /-. .31 /-.14$ & $.05 / .05 / .60$ & $-.41 /-.32 /-.60$ & $-.30 /-.35 / .15$ & $.14 / .19 / .50$ & $.26 /-.07 / .55$ & \\
\hline Satisfaction & $.05 / .07 / .69$ & $.04 /-.02 / .27$ & $-.04 / .18 /-.03$ & $-.07 / .05 /-.02$ & $.02 / .43 / .28$ & $-.01 / .09 /-.26$ & $5 \quad .56 / .49 / .67$ & $.39 / .41 / .07$ & $-.23 /-.18 /-. .30$ & $0-.42 /-.21 /-.35-$. & $.24 /-.52 /-.45$ \\
\hline
\end{tabular}

Note. $N=949$ session-specific assessments (Level 1: variable-specific) that are clustered within 513 teaching weeks (Level 2:

variable-general) of a total of 108 teachers (Level 3: stable-general). Present are correlation coefficients on Level 1 / Level 2 / Level 3.

Statistically significant $(p<.05)$ correlation coefficients are boldfaced. All correlations were modeled simultaneously in a

comprehensive model (Bayesian Posterior Predictive P-Value: .46).

also revealed another noteworthy finding regarding the association of the achievement goals: The correlations between the different goals were typically stronger on the teacher level than on the session-specific levels. This was especially the case for task approach and learning approach goals as well as performance approach and performance avoidance goals.

The results of the conducted three-level analyses (Table 3) indicated that mastery goals were related to more positive and less negative emotions. Interestingly, we only found these effects for task approach goals but not for learning goals. Furthermore, we primarily saw these effects on the teacher level but not the sessionspecific or week-specific level (for which the parameter estimates were descriptively also mostly much smaller). An exception to this was the link with shame, which we also found on the week-level.

Performance goals were less clearly related to the affective experiences. On the teacher level, performance approach goals went along with increased pride and decreased shame. On the week-level, these goals also went along with increased satisfaction. Performance avoidance goals, in turn, also went along with increased shame as well as anxiety on the teacher level. Further, pursuing stronger performance avoidance
Relational goals were associated with increased enjoyment, decreased boredom, and increased pride and satisfaction. We found these effects primarily on the week-specific as well as the teacher-specific level, but not on the session-specific level. Finally, work avoidance goals went along with less enjoyment and more boredom and shame on the teacher-specific level and were also related to pride. However, for pride, we observed different effects for the investigated levels. On the session-specific level, work-avoidance goals went along with decreased pride, however, on the week-specific level, with increased pride.

\section{Discussion}

We proposed and tested a conceptual framework that provides the foundation for a nuanced conceptualization of between- and within-person variety in teachers' goals as well as their subjective well-being (discrete emotions and satisfaction with teaching). We found that half of the variability in goal pursuit could be attributed to a stable-general fraction of variation (different teachers), but that goal pursuit also had substantial amounts of variable-general (different semester weeks of the teachers), stable-specific (different courses of the teachers), and variable-specific (remaining session variance) fractions. Emotions and satisfaction also contained these four fractions to a substantial 
Table 3

Results of 3-Level Regression Analyses on the Associations Between Achievement Goals and Emotions/Satisfaction

\begin{tabular}{|c|c|c|c|c|c|c|}
\hline & $\begin{array}{l}\text { Model 1: } \\
\text { Enjoyment }\end{array}$ & $\begin{array}{l}\text { Model 2: } \\
\text { Pride }\end{array}$ & $\begin{array}{l}\text { Model 3: } \\
\text { Anxiety }\end{array}$ & $\begin{array}{l}\text { Model 4: } \\
\text { Shame }\end{array}$ & $\begin{array}{l}\text { Model 5: } \\
\text { Boredom }\end{array}$ & $\begin{array}{c}\text { Model 6: } \\
\text { Satisfaction }\end{array}$ \\
\hline \multicolumn{7}{|l|}{ Achievement goals } \\
\hline Task approach & $.09 / .04 / .15$ & $.08 / .12 /-.23$ & $.04 /-.33 /-.36$ & $-.20 / .28 /-.34$ & $-.05 /-.13 /-.26$ & $.05 / .16 / .63$ \\
\hline Learning approach & $.02 / .13 / .18$ & $.02 / .19 / .12$ & $.12 /-.17 / .25$ & $.04 / .01 / .15$ & $.08 /-.13 / .05$ & $.06 /-.14 /-.04$ \\
\hline $\begin{array}{l}\text { Performance } \\
\text { (appearance) approach }\end{array}$ & $.09 / .01 / .07$ & $-.01 /-.08 / .29$ & $.06 / .35 /-.14$ & $-.08 / .15 /-.33$ & $-.09 / .05 / .13$ & $-.04 / .30 /-.01$ \\
\hline $\begin{array}{l}\text { Performance } \\
\text { (appearance) avoidance }\end{array}$ & $-.16 / .28 /-.13$ & $-.02 / .22 / .17$ & $-.07 / .01 / .26$ & $.18 /-.13 / .33$ & $.08 / .15 / .09$ & $-.06 /-.18 /-.18$ \\
\hline Relational & $.01 / .31 / .22$ & $-.03 / .32 / .15$ & $.01 /-.19 / .15$ & $-.04 /-.23 / .21$ & $.04 /-.28 /-.20$ & $.01 / .31 / .16$ \\
\hline Work avoidance & $.10 /-.15 /-.21$ & $-.10 / .33 /-.07$ & $-.08 / .12 / .13$ & $-.11 / .19 / .20$ & $.01 / .16 / .35$ & $.01 /-.04 / .03$ \\
\hline$R^{2}$ & $.06 / .28 / .26$ & $.03 / .36 / .30$ & $.07 / .32 / .26$ & $.12 / .37 / .29$ & $.04 / .24 / .34$ & $.02 / .25 / .46$ \\
\hline
\end{tabular}

Note. $N=949$ session-specific (Level 1: variable-specific) that are clustered within 513 teaching weeks (Level 2: variable-general)

of a total of 108 teachers (Level 3: stable-general). Present are standardized regression coefficients on Level 1 / Level 2 / Level 3.

Statistically significant $(p<.05)$ parameter estimates are boldfaced. Bayesian Posterior Predictive P-Values for the models: .41-.53.

extent, exhibited lower stable-general fractions than goals, and were systematically related to the achievement goals, with different effects being observable for the different levels. This illuminates the extent of temporal variability and context specificity and indicates that at least in the teaching domain, different effects may be observed depending on the different sources of variation.

\section{Differentiating Temporal Stability and Domain Specificity}

Our investigation into the temporal stability and context specificity of achievement goals was grounded in the notion that achievement goals describe an aspect of motivation that is influenced by a multitude of factors bound to dispositional characteristics as well as aspects of the context or the situation (Kaplan \& Maehr, 2007). To shed light on the situative construction of goals and the role of dispositions in this construction, our theoretical model defines four sources of variation that characterize achievement goal pursuit. Confirming our expectations and in line with previous research on school teachers (e.g., Praetorius et al., 2014) and students (e.g., Bong, 2004; Sparfeldt et al., 2015), we found that achievement goals for teaching have both temporally stable and variable as well context specific and general fractions.

Here, we observed that the stable-general fraction was larger than the other fractions and account for half of the variability in goal pursuit. This implies that a given teacher tends, to a large extent, to pursue similar achievement goals regardless of situational influences. Thus, achievement goals can be considered a sensible avenue to characterize inter-individual differences in teacher motivation. However, we also found that specific and variable aspects mattered for goal pursuit (referring to the respective courses or sessions that a teacher was teaching or the week that they were teaching in).

This was especially the case for task approach goals, which exhibited more variability on the session level than the other goals. These findings extend prior research suggesting that mastery goals are less stable than the other goals (Praeterious et al., 2014) in two ways: First, we only observed this pattern for task approach but not learning approach goals, pointing to different mechanics immanent in pursuing these goals. Second, this greater variability in task goals remaining within teachers was due to both variable as well as context specific fractions. This implies that teachers adjust their task goal pursuit according to the demands of the current situation (e.g., the workload in a given week) and the affordances of the current context (e.g., difficulty of the session to be taught) to a greater extent than their learning goals.

Alongside achievement goals, we also found teachers' emotions and satisfaction to have both temporally stable/variable and context specific/general fractions, which indicates that our proposed model on temporal stability and context specificity also extends to these constructs. This stands in line with prior research on emotions experienced in educational settings (see Nett et al., 2017; Respondek et al., 2019), as well as our findings for achievement goals in the present study, which affirms that, similar to achievement goal research, also for subjective well-being research, considering not only 


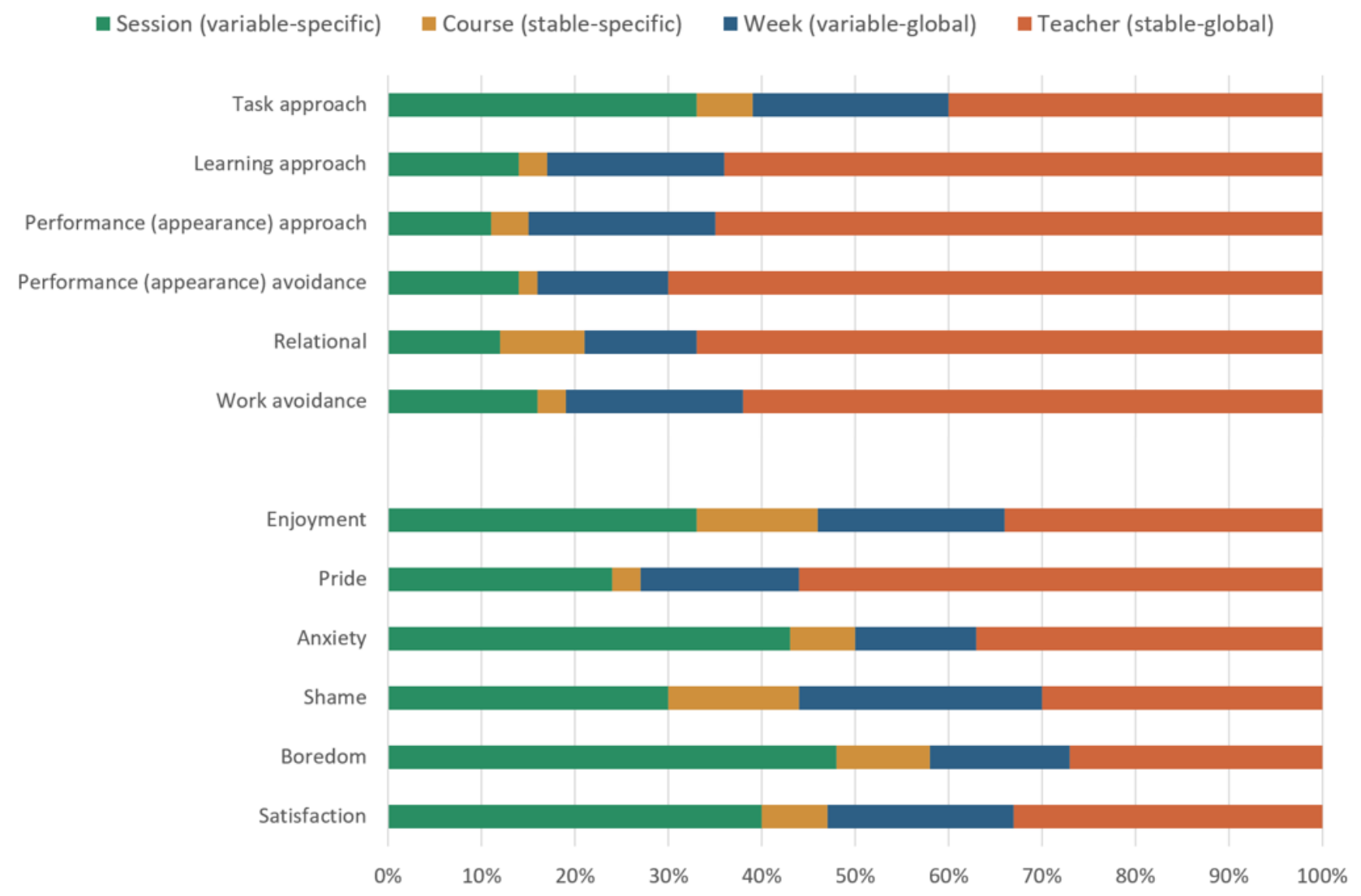

Figure 3. Visualization of the temporally variable and context specific

fractions of achievement goals and affective experiences.

a state and trait perspective, but a more specific elucidation of general and variables aspects of state variability, seems warranted. An interesting observation was that emotions and satisfaction exhibited lower stablegeneral fractions than achievement goals did (with the exception of pride). An explanation for this might lie in achievement goals being focused on desired states in the future, while emotions and satisfaction are evaluations of a current situation. Thus, goals might be construed in a more abstract form that renders them more stable and general than emotions and satisfaction, whose emergence can depend more strongly on critical events during teaching.

\section{Linkages Between Goals and Subjective Well-be- ing: Different Effects for Different Fractions of Sta- bility and Specificity?}

In terms of the linkages of achievement goals with emotions and satisfaction, our findings confirmed that these constructs are meaningfully and intricately intertwined and helped shed further light on the nature of these associations with regard to which specific fractions of these constructs are related to each other.
The overall patterns of associations with strong mastery, performance approach, and relational goals and weak performance avoidance and work avoidance goals being tied to more positive emotions and satisfaction and less negative emotions confirmed our expectations and largely fell in line with prior research (e.g., Daumiller et al., 2019; Janke et al., 2019; Rinas et al., 2020; Wang et al., 2016). Notably, concerning mastery approach goals, task approach goals were primarily adaptive (with the exception of pride, for which we observed a negative effect). The non-significant effects for learning approach goals may not be surprising, as studies that have simultaneously examined task and learning approach goals with affective variables have also found effects for solely one or the other (e.g., Daumiller et al., 2019; Rinas et al., 2020), and research indicated that for teachers (opposed to students where the main task usually is defined by learning and improving own competences), task and learning goals may enfold distinct effects. Given the short time frame in which we investigated achievement goals, the pursuit of complex learning goals might have not have been feasible. Thus, 
we believe that the distinction between learning and task goals, and a consideration of moderators to illuminate when the respective goals might particularly matter, could be an important future step to disentangle further how mastery goals matter for subjective well-being.

Besides largely confirming the expected linkages between goals and emotions and satisfaction, the main contribution of our study with regard to the link between goals and subjective well-being is that our findings indicate that these linkages can differ depending on the different stability and specificity fractions. This stands in contrast to the findings by Goetz et al. (2016) that did not indicate variation in relationships between goals and emotions depending on the within or between level. Our findings paint a more nuanced picture of the relationship between goals and emotions which might be a function of the finer conceptualization of betweenand within-person variation (Figure 1) or the consideration of a population where goals and emotions may be linked in a more complex way. In particular, we found linkages between goals and subjective well-being on all three levels, with the majority located on the stableglobal level and only few on the variable-specific level. Most of these linkages were only found on one of these levels and not on the other levels as well.

For example, we primarily observed the associations of task and work avoidance goals on the stablegeneral level. This means that individual differences in these goals are particularly important for explaining teachers' emotional experiences, possibly because they impact teachers' general preparation for teaching. One may reason that a general orientation towards optimal resource and time allocation has more impact on feelings of accomplishment than respective intentions for a singular course or session as such intentions will likely fall flat if not embedded in an overarching plan. Future research should follow up on this by also considering third variables that might explain these differential linkages further (e.g., experience with teaching particular sessions or courses).

As our study was primarily directed at uncovering the different level of stability/specificity of teachers' goals and uncovering if these may matter for their linkages with subjective well-being, we do not want to overinterpret the particular effects, but believe that they serve as indications for potential different linkages on the different levels. Including what "happens" in a particular session or week, in terms of employed teaching strategies, student reactions, and other obligations of the teachers, seems to be an important avenue for investigating these linkages in detail in future research.

\section{Limitations, Future Research Directions, and Prac- tical Implications}

Interpreting our findings, it should be borne in mind that we assessed achievement goals at the beginning of each session and emotions/satisfaction at the end. This means that on the session level, the linkages between goals and emotions likely represent effects from goals on emotions, while on the other levels, the linkages are also conflated with reverse and reciprocal effects. For work avoidance goals for example, this could mean that experiences of maladaptive emotions and satisfaction, which are an indicator of compromised well-being, might elicit pursuit of stronger work avoidance goals as a coping mechanism (see Authors, anonymized). This might thus lead to stronger effects on the stable-general level compared to smaller effects on the variable-specific level. Thus, future longitudinal or experimental research is warranted to further elucidate the mechanisms behind these associations.

Further, it should be considered that we surveyed teachers for five weeks and that the different contexts that we considered (different courses) are usually more closely aligned than, for example, different subjects of students (with vastly different valuations and characteristics). It stands to reason that if we had we surveyed the teachers for a longer time frame (e.g., half a year), the temporally variable fractions would have been larger. The same goes for investigations of different work domains (such as teaching and research). However, it is worth noting that the research works that considered temporal stability of achievement goals over half a year (e.g. Daumiller \& Dresel, 2020b) or their associations between teaching and research (Daumiller \& Dresel, 2020a), also found around half of the variability in achievement goals being temporally stable or general across the two domains. Thus, it is likely that our results would not have changed very significantly if a longer time frame or more contexts were considered. This goes along well with the largely similar stability findings of achievement across different populations, contexts, and time-intervals, speaking to universal attributes of achievement goal pursuit. Nevertheless, it would be interesting for future research to follow up on this by considering different contexts and time frames. We believe that our model can provide a sensible starting place for such investigations in order to illuminate the temporal stability and context specificity of achievement goal pursuit further.

Further caution in interpreting the exact magnitude of the different stability and specificity fractions is warranted because the teachers in our sample participated on average with a larger number of weeks than of 
courses, potentially making it more difficult to find systematic variability bound to the course level. Also, it should be considered that session specific variability also contains measurement error besides actual sessionspecific variance fractions. While the single item scales that we used have been shown to have high reliability in past research and the associations between the assessed constructs do imply high systematic variation, the exact magnitude of variable-specific fractions might still be overestimated.

Finally, it should be noted that achievement goals, emotions, and teaching satisfaction were measured solely through self-report measures. Given that goals and satisfaction are cognitive constructs, this approach is very well suited for them. Emotions are widely assessed through self-reports too, however, also other methods might be considered to be supplemented in the future to avoid same-source biases (such as physiological measures or behavioral observations of emotions during teaching).

In terms of implications for future research and practice, one important point that can be derived from our study was that achievement goals were found to be malleable. This marks an encouraging step for intervention development research aimed at fostering more adaptive achievement goals in teachers. Additionally, from our findings we can conclude that achievement goals are situated. Therefore, addressing achievement goals not only on a general level, but also regarding, for example, in a given week or specific sessions, may provide critical information when seeking to assess or alter goal pursuit. An interesting observation that can inspire future research was further that the often fairly high correlations between performance approach and avoidance goals were primarily found on the stable-general level, but not so much on the specific and variable levels. This implies that individuals who may be driven by high performance motivation pursue either performance approach or performance avoidance goals depending on aspects of the specific achievement situation. Examining theoretically relevant moderators, such as perceived competence regarding the current situation (see hierarchical model by Elliot, 2006), would thereby be an interesting future research avenue to help elucidate differences in (performance) goal pursuit further.

\section{Conclusion}

Through investigating achievement goals for teaching specific sessions, we found that half of the variability in goal pursuit could be attributed to a stable-general fraction (different teachers), but that goal pursuit also had substantial amounts of variable-general (different semester weeks of the teachers), stable-specific (different courses of the teachers), and variable-specific (remaining session variance) fractions. Affective experiences also contained these four fractions to a substantial extent and were systematically related to the achievement goals, with different effects being observable for the different levels. This illuminates the extent of temporal variability and context specificity in achievement goals, emotions, and satisfaction and indicates that, at least in the teaching context, different effects may be observed depending on the different fractions of these constructs. Taken together, our results contribute to a better understanding of the variability of higher education teachers' achievement goals for teaching, and how this is associated with variability in their experiences of discrete emotions and satisfaction. These findings can thereby act as a stepping stone for future research aimed at elucidating and supporting higher education teachers' goals and well-being concerning their teaching activities and beyond.

\section{References}

Becker, E. S., Goetz, T., Morger, V., \& Ranellucci, J. (2014), The importance of teachers' emotions and instructional behavior for their students' emotions. Teaching and Teacher Education, 43, 15-26. https://doi.org/10.1016/j.tate.2014.05.002

Bong, M. (2001). Between-and within-domain relations of academic motivation among middle and high school students. Journal of Educational Psychology, 93, 23-34. https://doi.org/10/fncvb5

Bong, M. (2004). Academic motivation in self-efficacy, task value, achievement goal orientations, and attributional beliefs. The Journal of Educational Research, 97, 287298. https://doi.org/10.3200/JOER.97.6.287-298

Bürger, K., \& Schmitt, M. (2017). Students' multiple state goals as a function of appraisals, trait goals, and their interactions. Contemporary Educational Psychology, 51, 464-481.

https://doi.org/10.1016/j.cedpsych.2017.09.006

Butler, R. (2007). Teachers' achievement goal orientations and associations with teachers' help-seeking. Journal of Educational Psychology, 99, 241-252. https://doi.org/10/fqf5tm

Butler, R. (2012). Striving to connect. Journal of Educational Psychology, 104, 726-742. https://doi.org/10.1037/a0028613

Daumiller, M., Bieg, S., Dickhäuser, O., \& Dresel, M. (2020). Humor in university teaching. Studies in Higher Education, 45(12), 26192633. https://doi.org/10.1080/03075079. 2019.1623772.

Daumiller, M., Dickhäuser, O., \& Dresel, M. (2019). University instructors' achievement goals for teaching. Journal 
of Educational Psychology, 111(1), 131-148. https://doi.org/10.1037/ edu0000271.

Daumiller, M., \& Dresel, M. (2020a). Teaching and research: Specificity and congruence of university faculty achievement goals. International Journal of Educational Research, 99. Advanced online publication. https://doi.org/10.1016/j.ijer.2019.08.002.

Daumiller, M., \& Dresel, M. (2020b). Researchers' achievement goals. Contemporary Educational Psychology, 61, 101843. https://doi.org/10.1016/j.cedpsych.2020.101843

Daumiller, M., Grassinger, R., Dickhäuser, O., \& Dresel, M. (2016). Structure and relationships of university instructors' achievement goals. Frontiers in Psychology, 7. https://doi.org/10/csd8

Daumiller, M., Rinas, R., \& Jaitner, D. (2021b). The relevance of stability and change of achievement goals for self-regulated motor learning processes and outcomes. Sport, Exercise, and Performance Psychology. https://doi.org/10.1037/spy0000260

Daumiller, M., Janke, S., Hein, J., Rinas, R., Dickhäuser, O., \& Dresel, M. (2021a). Do teachers' achievement goals and self-efficacy beliefs matter for students' learning experiences. Learning and Instruction. https://doi.org/10.1016/j.learninstruc.2021.101458.

Diener E., Napa Scollon C., Lucas R.E. (2009) The evolving concept of subjective well-being. In Diener E. (Ed.), Assessing well-being. Social indicators research series. Springer. https://doi.org/10.1007/978-90-481-2354-4_4

Dresel, M., Fasching, M., Steuer, G., Nitsche, S., \& Dickhäuser, O. (2013). Relations between teachers' goal orientations, their instructional practices and student motivation. Psychology, 4, 572-584. https://doi.org/10.4236/psych.2013.47083

Elliot, A. J. (2006). The hierarchical model of approachavoidance motivation. Motivation and Emotion, 30(2), 111-116. https://doi.org/10.1007/s11031-006-9028-7

Elliot, A. J., \& Hulleman, C. S. (2017). Achievement goals. In A. J. Elliot, C. S. Dweck, \& D. S. Yeager (Eds.), Handbook of competence and motivation, (pp. 43-60). Guilford.

Elliot, A. J. \& McGregor, H. A. (2001). A $2 \times 2$ achievement goal framework. Journal of Personality and Social Psychology, 80, 501-519. https://doi.org/10.1037/00223514.80.3.501

Elliot, A. J., Murayama, K., \& Pekrun, R. (2011). A $3 \times 2$ achievement goal model. Journal of Educational Psychology, 103(3), 632-648. https://doi.org/10.1037/a0023952

Frenzel, A. C., Becker-Kurz, B., Pekrun, R., \& Goetz, T. (2015). Teaching this class drives me nuts. PLOS ONE, 10(6), e0129630. https://doi.org/10.1371/journal.pone. 0129630

Frenzel, A. C., Pekrun, R., Goetz, T., Daniels, L. M., Durksen, T. L., Becker-Kurz, B., \& Klassen, R. M. (2016). Measuring teachers' enjoyment, anger, and anxiety. Contemporary Educational Psychology, 46, 148-163. https://doi.org/10.1016/j.cedpsych.2016.05.003
Fryer, J. W., \& Elliot, A. J. (2007). Stability and change in achievement goals. Journal of Educational Psychology, $99, \quad 700-714 . \quad$ https://doi.org/10.1037/0022 0663.99.4.700

Goetz, T., Preckel, F., Pekrun, R., \& Hall, N. C. (2007). Emotional experiences during test taking. Learning and Individual Differences, 17(1), 3-16.

Goetz, T., Sticca, F., Pekrun, R., Murayama, K., \& Elliot, A. J. (2016). Intraindividual relations between achievement goals and discrete achievement emotions. Learning and Instruction, $41, \quad 115-125$. https://doi.org/10.1016/j.learninstruc.2015.10.007

Gogol, K., Brunner, M., Goetz, T., Martin, R., Ugen, S., Keller, U., ... Preckel, F. (2014). "My Questionnaire is Too Long!”. Contemporary Educational Psychology, 39(3), $188-205$.

https://doi.org/10.1016/j.cedpsych.2014.04.002

Grant, H., \& Dweck, C. (2003). Clarifying achievement goals and their impact. Journal of Personality and Social Psychology, 85, 541-553. https://doi.org/10.1037/00223514.85.3.541

Hein, J., Daumiller, M., Janke, S., Dresel, M., \& Dickhäuser, O. (2019). How learning time mediates the impact of university scholars' learning goals on professional learning in research and teaching. Learning and Individual Differences, $\quad 72, \quad 15-25 . \quad$ https://doi.org/10.1016/j.lindif.2019.04.002

Hein, J., Janke, S., Daumiller, M., Dresel, M. \& Dickhäuser, O. (2020). No learning without autonomy. Learning and Individual Differences, 83/84(Article 101937), 1-31. https://doi.org/10.1016/j.lindif.2020.101937

Huang, C. (2011). Achievement goals and achievement emotions: A meta-analysis. Educational Psychology Review, 23, 359-388. https://doi.org/10.1007/s10648-011-9155$\mathrm{x}$

Hulleman, C. S., Schrager, S., Bodmann, S., \& Harackiewicz, J. (2010). A meta-analytic review of achievement goal measures. Psychological Bulletin, 136, 422-449. https://doi.org/10/dkdjkc

Jagacinski, C. M., Kumar, S., Boe, J. L., Lam, H., \& Miller, S. A. (2010). Changes in achievement goals and competence perceptions across the college semester. Motivation and Emotion, 34(2), 191-204. https://doi.org/10.1007/s11031-010-9165-x

Janke, S., Bardach, L., Oczlon, S., \& Lüftenegger, M. (2019). Enhancing feasibility when measuring teachers' motivation. Teaching and Teacher Education, 83, 1-11. https://doi.org/10.1016/j.tate.2019.04.003

Janke, S., \& Dickhäuser, O. (2018). A situated process model of vocational achievement goal striving within members of the academic staff at university. Motivation and Emotion, 42, 1-16. https://doi.org/10.1007/s11031-0179657-z

Kaplan, A., \& Maehr, M. L. (2006). The contributions and prospects of goal orientation theory. Educational Psychology Review, 19(2), 141-184. https://doi/org/10.1007/s10648-006-9012-5 
Kiltz, L., Rinas, R., Daumiller, M., Fokkens-Bruinsma, M., \& Jansen, E. P. W. A. (2020). 'When they struggle, I cannot sleep well either'. Frontiers in Psychology, 11(578378), $1-18$. https://doi.org/10.3389/fpsyg.2020.578378

King, R. B., \& McInerney, D. M. (2014). The work avoidance goal construct. Contemporary Educational Psychology, 39(1),

$42-$ 58. https://doi.org/10.1016/j.cedpsych.2013.12.002

Lee, M., \& Bong, M. (2016). In their own words: Reasons underlying the achievement striving of students in schools. Journal of Educational Psychology, 108(2), 274-294. https://doi.org/10.1037/edu0000048

Muis, K. R., \& Edwards, O. (2009). Examining the stability of achievement goal orientation. Contemporary Educational Psychology, 34(4), 265-277. https://doi.org/10.1016/j.cedpsych.2009.06.003

Murayama, K., Elliot, A. J., \& Yamagata, S. (2011). Separation of performance-approach and performance-avoidance achievement goals. Journal of Educational Psychology, 103, 238-256. https://doi.org/10.1037/a0021948

Murayama, K., Goetz, T., Malmberg, L.-E., Pekrun, R., Tanaka, A., \& Martin, A. J. (2017). Within-person analysis in educational psychology. In D. W. Putwain \& K. Smart (Eds.), British Journal of Educational Psychology Monograph Series II. Wiley.

Murphy, P. K., \& Alexander, P. A. (2000). A motivated exploration of motivation terminology. Contemporary Educational Psychology, 25(1), 3-53. https://doi.org/10.1006/ceps.1999.1019

Muthén, L., \& Muthén, B. (2017). Mplus (version 8.1) [Computer Software]. Los Angeles, CA: Muthén \& Muthén.

Nett, U. E., Bieg, M., \& Keller, M. M. (2017). How much trait variance is captured by measures of academic state emotions? European Journal of Psychological Assessment, 33(4), 239-255. https://doi.org/10.1027/1015$5759 / \mathrm{a} 000416$

Papaioannou, A., \& Christodoulidis, T. (2007). A measure of teachers' achievement goals. Educational Psychology, 27(3), 349-361. https://doi.org/10.1080/01443410601104148

Parker, P. D., Martin, A. J., Colmar, S., \& Liem, G. A. (2012). Teachers' workplace well-being. Teaching and Teacher Education, 28, 503-513. https://doi.org/10.1016/j.tate.2012.01.001

Pekrun, R., Elliot, A. J., \& Maier, M. A. (2006). Achievement goals and discrete achievement emotions. Journal of Educational Psychology, 98(3), 583-597. https://doi.org/10.1037/0022-0663.98.3.583

Pekrun, R., Elliot, A. J., \& Maier, M. A. (2009). Achievement goals and achievement emotions. Journal of Educational Psychology, 101(1), 115-135. https://doi.org/10.1037/a0013383

Pekrun, R., Goetz, T., Frenzel, A. C., Barchfeld, P., \& Perry, R. P. (2011). Measuring emotions in students' learning and performance. Contemporary Educational Psychology, 36(1), 36-48. https://doi.org/10.1016/j.cedpsych.2010.10.002

Peugh, J. L., \& Enders, C. K. (2004). Missing data in educational research. Review of Educational Research, 74, 525-556. https://doi.org/10.3102/00346543074004525

Pintrich, P. R. (2000). Multiple goals, multiple pathways. Journal of Educational Psychology, 92(3), 544-555. https://doi.org/10.1037/0022-0663.92.3.544

Praetorius, A.-K., Nitsche, S., Janke, S., Dickhäuser, O., Drexler, K., Fasching, M., \& Dresel, M. (2014). Here today, gone tomorrow. Contemporary Educational Psychology, 39, 379-387. https://doi.org/10/csfw

Respondek, L., Seufert, T., \& Nett, U. E. (2019). Adding previous experiences to the person-situation debate of achievement emotions. Contemporary Educational Psychology, 58, 19-32. https://doi.org/10.1016/j.cedpsych.2019.02.004

Retelsdorf, J., Butler, R., Streblow, L., \& Schiefele, U. (2010). Teachers' goal orientations for teaching. Learning and Instruction, 20, 30-46. https://doi.org/10.1016/j.learninstruc.2009.01.001

Retelsdorf, J., \& Günther, C. (2011). Achievement goals for teaching and teachers' reference norms. Teaching and Teacher Education, 27, 1111-1119. https://doi.org/10.1016/j.tate.2011.05.007

Rinas, R., Dresel, M., Hein, J., Janke, S., Dickhäuser, O., \& Daumiller, M. (2020). Exploring university instructors' achievement goals and discrete emotions. Frontiers in Psychology, 11(1484), 1-13. https://doi.org/10.3389/fpsyg.2020.01484

Scherrer, V., Preckel, F., Schmidt, I., \& Elliot, A. J. (2020). Development of achievement goals and their relation to academic interest and achievement in adolescence. Developmental Psychology, 56(4), 795-814. https://doi.org/10.1037/dev0000898

Senko, C., \& Dawson, B. (2017). Performance-approach goal effects depend on how they are defined. Journal of Educational Psychology, 109(4), 574-598. https://doi.org/10.1037/edu0000160

Senko, C., Hulleman, C., \& Harackiewicz, J. (2011). Achievement goal theory at the crossroads. Educational Psychologist, $46, \quad$ 26-47. https://doi.org/10.1080/00461520.2011.538646

Seo, E., \& Patall, E. A. (2020). Feeling proud today may lead people to coast tomorrow. Emotion. Advance online publication. https://doi.org/10.1037/emo0000752

Skaalvik, E. M., \& Skaalvik, S. (2011). Teacher job satisfaction and motivation to leave the teaching profession. Teaching and Teacher Education, 27, 1029-1038. https://doi.org/10/dpnv28

Sparfeldt, J. R., Brunnemann, N., Wirthwein, L., Buch, S. R., Schult, J., \& Rost, D. H. (2015). General versus specific achievement goals. Learning and Individual Differences, 43, 170-177. $\quad$ https://doi.org/10.1016/j.lindif.2015.08.022 
Stupnisky, R. H., Hall, N. C., \& Pekrun, R. (2019). The emotions of pretenure faculty. The Review of Higher Education, 42(4), $1489-1526$. https://doi.org/10.1353/rhe.2019.0073

Stupnisky, R. H., Pekrun, R., \& Lichtenfeld, S. (2016). New faculty members' emotions. Studies in Higher Education, 41(7), https://doi.org/10.1080/03075079.2014.968546

Thies, K., \& Kordts-Freudinger, R. (2019). University academics' state emotions and appraisal antecedents. Studies in Higher Education, 44(10), 1723-1733. https://doi.org/10.1080/03075079.2019.1665311

Voelkle, M. C., Brose, A., Schmiedek, F., \& Lindenberger, U. (2014). Toward a unified framework for the study of between-person and within-person structures. Multivariate Behavioral Research, 49(3), 193-213. https://doi.org/10.1080/00273171.2014.889593

Wang, H., Hall, N., Goetz, T., \& Frenzel, A. (2016). Teachers' goal orientations. British Journal of Educational
Psychology, $\quad$ 87, 90-107. https://doi.org/10.1111/bjep.12137

Wright, A. G. C., \& Zimmermann, J. (2019). Applied ambulatory assessment. Psychological Assessment, 31(12), 1467-1480. https://doi.org/10.1037/pas0000685

Yasuda, T., Lawrenz, C., van Whitlock, R., Lubin, B., \& Lei, P. W. (2004). Assessment of intraindividual variability in positive and negative affect using latent state-trait model analyses. Educational and Psychological Measurement, 64, 514-530. https://doi.org/: $10.1177 / 0013164403258445$

Note. This is a pre-copyedited, author-produced PDF of an article submitted for publication. This paper is not the copy of record and may not exactly replicate the final, authoritative version of the article. The final article will be available, upon publication, via its DOI. 


\section{Footnotes}

${ }^{1}$ We assessed mastery avoidance and normative goals for reasons of completeness and examined them in ancillary analyses. They had similar ICCs as the corresponding mastery approach and appearance goals.

${ }^{2}$ In Germany it is common for doctoral candidates to be hired as university faculty members. They pursue their Ph.D. alongside fulfilling official teaching and research responsibilities. This leads to a larger share of faculty members without Ph.D. in Germany compared to countries than the U.S. where doctoral candidates mainly focus on their own studies rather than simultaneously working as university faculty.

${ }^{3}$ To test the robustness of the effects, we reran all models reported with week as level 2 (instead of courses) and found that all effects on the other two levels held robust for this alternative hierarchical structure). 